\title{
Large-Scale Microwave Remote Sensing of Retrieving Surface Multi-parameters Using Active and Passive Satellite Data: In the Tibetan Plateau Region of Maqu
}

\author{
Ruofei Zhong ${ }^{1}$, Jianxi Huang ${ }^{2, *}$, Jiangxia Wei ${ }^{1}, \mathrm{Qin}{ }^{1}$, Jiao Guo ${ }^{1}$, and Wei $\mathrm{Su}^{2}$ \\ ${ }^{1}$ Capital Normal University Key Lab of 3D Information Acquisition and Application, \\ MOE, Beijing 100048, China \\ zrfgis@263.net \\ ${ }^{2}$ College of Information \& Electrical Engineering, China Agricultural University, \\ Beijing, P.R. China, 100083
}

\begin{abstract}
To conduct with these land surface parameters inversion using microwave observations in the bare soil surface, it is needed to estimate soil moisture (SM), surface temperature (ST) and surface roughness changes with microwave observations. High-frequency passive microwave radiometer sensitivity of the roughness is very low, traditional ground truth can't provide an accurate large-scale roughness of pixel information, and active radar and scatterometer data for roughness of the high sensitivity, active and passive joint inversion of soil volumetric water content is the current hot research. The main objective of this research is to develop a suitable method instead of some traditional methods for the retrieval of SM and other parameters at large-scale, which is based on the synergistic use of AMSR-E and Quikscat/SeaWinds observations. Quikscat / SeaWinds can provide large-scale scatterometer data, first used in this study to establish AIEM simulation and backscattering coefficient of roughness between, and then estimate the roughness of the known information as auxiliary inversion surface AMSR-E temperature and soil volumetric water content. The retrieval results show that this proposed method is helpful to achieve a higher accuracy in the study region of Maqu.
\end{abstract}

Keywords: AMSR-E, QuikSCAT/Seawinds, Surface temperature, Soil moisture, Roughness.

\section{Introduction}

Bare ground or sparse vegetation in surface conditions, AMSR-E inversion of soil surface roughness and time-sharing need to consider the effect of temperature. Traditional methods for estimating the roughness of the signal for the major impact of microwave radiation is used calibration method or empirical method, but the drawback of the calibration methods influenced by the sample with the measured roughness no definite link, although the empirical method related to the measured

\footnotetext{
* Corresponding author.
} 
roughness, but the local applicability. AIEM model simulation analysis can be used to know: when the frequency similar to the initiative of the roughness of the sensitivity of the microwave signal was significantly higher than the passive microwave signal, active and passive with a more accurate estimate of roughness, which could improve the accuracy of soil moisture. Inversion of a variety of active and passive sensors SMAP soil moisture is the core mission plan.

The current study of active and passive joint inversion of soil moisture remote sensing data sharing, targeted active and passive sensors are mostly equipped with a satellite, such as TRMM, PALSAR, etc. (Wu, etc., 2006; Chen, etc., 2008), mainly in order to obtain synchronous data. Equipped with different sensors on the satellite joint inversion of the current post less, mainly due to different satellites through the same area of the transit time differences (in hours), in this time interval the surface with a pixel parameter information has changed. In addition, despite recent high spatial resolution of radar data inversion for soil water into a hot spot, but the large-scale spatial and temporal distribution of soil moisture monitoring for global change research still has an irreplaceable position. ZHONG et al (2006) with the AMSR-E and Quikscat / SeaWinds joint inversion of soil moisture research work directly to the scattering of dollars to a VV polarization channel radiometer with two low-frequency channels in the multi-input inversion parameters of the inversion, ignoring the two sensors is not at the same time to obtain the surface information, and the results show that soil moisture sensor for two different sensitivity in the AMSR-E on the basis of observations by adding Quikscat / SeaWinds of channel has not improved with the iterative inversion accuracy. Some researchers are using experimental data analysis Quikscat / SeaWinds on soil moisture sensitivity, they noted that: Quikscat / SeaWinds Only in very dry and very wet soil conditions are more sensitive to soil moisture, and the results of extracting soil moisture information still not ideal (Scipal etc., 2002; Mladenova, etc., 2009; Zyl, etc.). These studies show that: the above two use Quikscat / SeaWinds collaborative way and can not get a good retrieval of soil moisture inversion.

Not a long period of time, except for special circumstances such as rainfall, that the surface roughness remains constant, this study based on this proposed new program: First, use the AIEM model simulations Quikscat / SeaWinds two different incidence angles different polarized backscattering coefficient and the roughness of the relationship, and then extract the roughness of the information and provide it to AMSR-E, further inversion of soil moisture and surface temperature.

\section{Study Region and Data}

This study area latitude and longitude of $33^{\circ} 30^{\prime}-34^{\circ} 15^{\prime} \mathrm{N}, 101^{\circ} 38^{\prime}-102^{\circ} 45^{\prime} \mathrm{E}$, ground-based data acquisition time for July 2008 to August, on-board data selection is Quikscat / Seawinds and AMSR-E passive microwave sensors to specific areas of Qinghai-Tibet Plateau to obtain the joint surface soil moisture data, Maqu mostly open grassland areas(Fig.1), vision, set in Maqu region collected 20 soil sites, (Fig.2) collecting data, including temperature, soil moisture, soil texture and so on.

As the sensor is relatively large field of view, this research work will be on a pixel is within the scope of the average number of sites, just remove the anomaly is equal to 
the minimum or maximum value, the last for the entire study area for all the pixels as a whole is to the simulation, choose the model chosen for the Qp model of radiation scattering model AIEM model, based on data measured on the ground to complete the forward simulation, and compared with actual observations.



Fig. 1. Typical landscape Maqu region: mountain (upper left), grassland and bare soil (upper right), Yellow (medium), Yellow (bottom left), wetlands (bottom right)

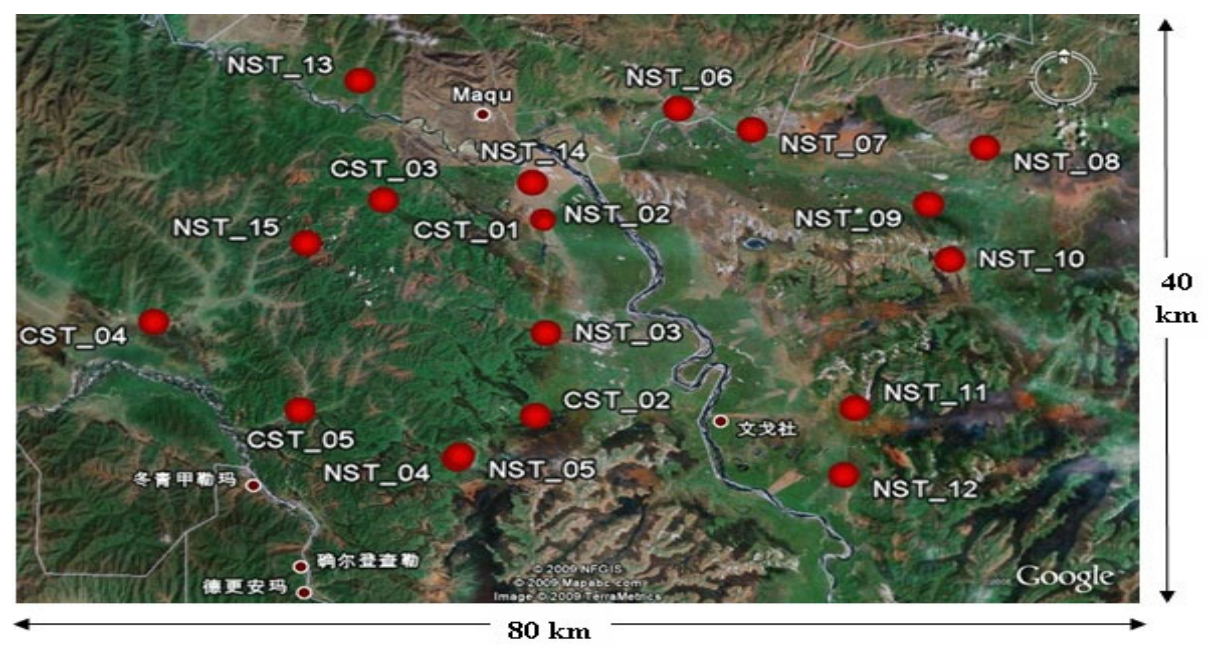

Fig. 2. Maqu region twenty maps of soil moisture collection site

According to this article, active and passive joint inversion scheme, first, using simulation databases established the relationship between the ratio of RMS height and the scattering coefficient and the difference of scattering plan two channels decibels, and then use Maqu region $\mathrm{HH}$ and VV scattering meter data to estimate the joint roughness slope information, as known parameters input to the microwave radiation model, which complete inversion of soil moisture. Here in order to eliminate measurement noise, the use of AMSR-E data in the 6.6GHZ frequency and 10.9GHZ 
two four-channel inversion, inversion of surface parameters to soil moisture and surface temperature inversion iterative algorithm for the LM .

\section{Physical Models and Retrieval Algorithm}

\subsection{Applicability of the Radiation Model}

Used in this study taking into account the characteristics of active and passive sensors, and according to Shi Jiancheng's research team conducted in recent years in the Tibetan Plateau soil moisture inversion of the published research literature and related information, choice of radiation model for the Qp model, scattering model AIEM model.

AIEM model does not consider part of coherent radiation or scattering, but because of Quikscat / Seawinds the angle of incidence of 46 and 54.1, relatively large, even in large areas of undulating terrain, it is hard for the local angle of incidence close to $0^{\circ}$, so the coherent scattering from formula to analyze, you can not consider it part of coherent scattering. Therefore, the model can be used to establish AIEM Quikscat / Seawinds analog observation database.

In the inversion of passive microwave soil moisture for bare surface of a variety of semi-empirical model, Shi and other articles will be in 2006, divided into three categories: Q/H model (1), Hp model (2) and Qp model (3). They form are:

$$
\begin{gathered}
\mathrm{R}_{\mathrm{p}}^{\mathrm{e}}=\left[1-\mathrm{r}_{\mathrm{op}}+\mathrm{Qr}_{\mathrm{op}}\right] \cdot \mathrm{H} \\
\mathrm{R}_{\mathrm{p}}^{\mathrm{e}}=\mathrm{r}_{\mathrm{op}} \mathrm{H}_{\mathrm{p}} \\
\mathrm{R}_{\mathrm{p}}^{\mathrm{e}}=\left[\left(1-\mathrm{Q}_{\mathrm{p}}\right) \mathrm{r}_{\mathrm{op}}+\mathrm{Q}_{\mathrm{p}} \mathrm{r}_{\mathrm{op}}\right.
\end{gathered}
$$

You can see, Hp model is Q / H model is based on the hypothesis Q = 0 obtained, Qp model at $\mathrm{Q} / \mathrm{H}$ model based on the hypothesis $\mathrm{H}=1$ to get. Qp model of $\mathrm{Hp}$ compared with $\mathrm{Q} / \mathrm{H}$ model, the advantage is that they considered the different polarization by roughness on the reflectivity of the impact.

In AMSR-E parameter conditions, with AIEM model to bare landmark Fresnel reflectivity research, there are two points found:

1. The effective reflectivity of surface with the frequency changes are caused by water in different frequency dielectric constant differences, but the roughness at different frequencies to the effective reflectivity of the image is relatively stable, does not change with increasing frequency and strong .

2. Compared to the flat case, $\mathrm{H}$ polarization in the rough surface will reduce the reflected energy, or the emission energy increases. In other words, the rough surface effective reflectivity $\mathrm{H}$ polarization is always lower than the corresponding smooth surface of the Fresnel reflectivity. But V polarization is opposite.

So it can be a direct result of the two as follows:

1. You can use a frequency the roughness of the parameters of the other frequency rough parameters. 
2. Polarization of the surface effective reflectivity of the rough calculation there are effects, not on $\mathrm{H}, \mathrm{V}$ polarization of the two kinds of roughness parameters equated.

Then, Shi and others with AIME, respectively, and Q / H model, Hp model and the Qp model 10.6GHz, 55-degree angle under the conditions of the simulation, and compare the results.

In the three semi-empirical model simulation results, Qp model and the best fit model results AIME, Q / $\mathrm{H}$ model followed, $\mathrm{Hp}$ model the worst. Investigate is reason, Hp model did not consider the error from the incoherent part, and in the case of highfrequency, non-coherent part of the effective reflection on the surface of the dominant. $\mathrm{Q} / \mathrm{H}$ model error from the $\mathrm{H}, \mathrm{V}$ two polarization roughness parameters under the same treatment.

Therefore, in this study, the use of parameters and roughness parameters Qp (s / l) relationship with the Qp model to simulate AMSR-E forward radiation reflectivity, enabling researchers to use a simple, single parameter roughness of the surface effective reflectivity model simulation and inversion.

\subsection{Scattering Parameters of the Model Sensitivity Analysis}

AIEM model can be used to simulate the exposed surface of the scatter meter data, but also to simulate bare surface radiometer data. Through model simulations, can be found: in the soil moisture, surface temperature, surface roughness and other parameters, the scatter meter data for roughness of the most sensitive, the sensitivity of other surface parameters is small; radiometer is most sensitive to soil moisture, surface temperature of the second, less sensitive to the roughness. Soil type and other soil parameters affecting radiation scatter meter data, but little impact.

Also, because the number of surface parameters, changes over time, soil moisture, surface temperature was greater than that roughness is essentially the same, in this study the use of active and passive microwave sensors to obtain data in the study area are not synchronized, Therefore, with the actual situation, the study of passive joint inversion method of soil moisture: the first with a scatter meter to estimate roughness slope, then the inversion of radiometric information with other surface roughness parameters, including soil moisture.

\section{Datainversion}

\subsection{Forward Modeling and Calibration of Radiation}

According to previous analysis of the applicability of the model, this study used a direct simulation of the model AIEM simulate the observations of scatter meter, the inversion may not process the general operation of the "model parameter calibration" work.

Simulated on a single site, there is insufficient data to use, and the method that points represent the surface of the simulation is not science. The research work will be on a pixel is within the scope of the average number of sites, just remove the anomaly equal to the maximum or minimum value, and finally the entire study area for all 
pixels whole forward simulation by the entire study area all the pixels in the four channels on the forward simulation results (Fig.3).


Coupaion of Brightness Tenperature of Satellite and Forrardlodel
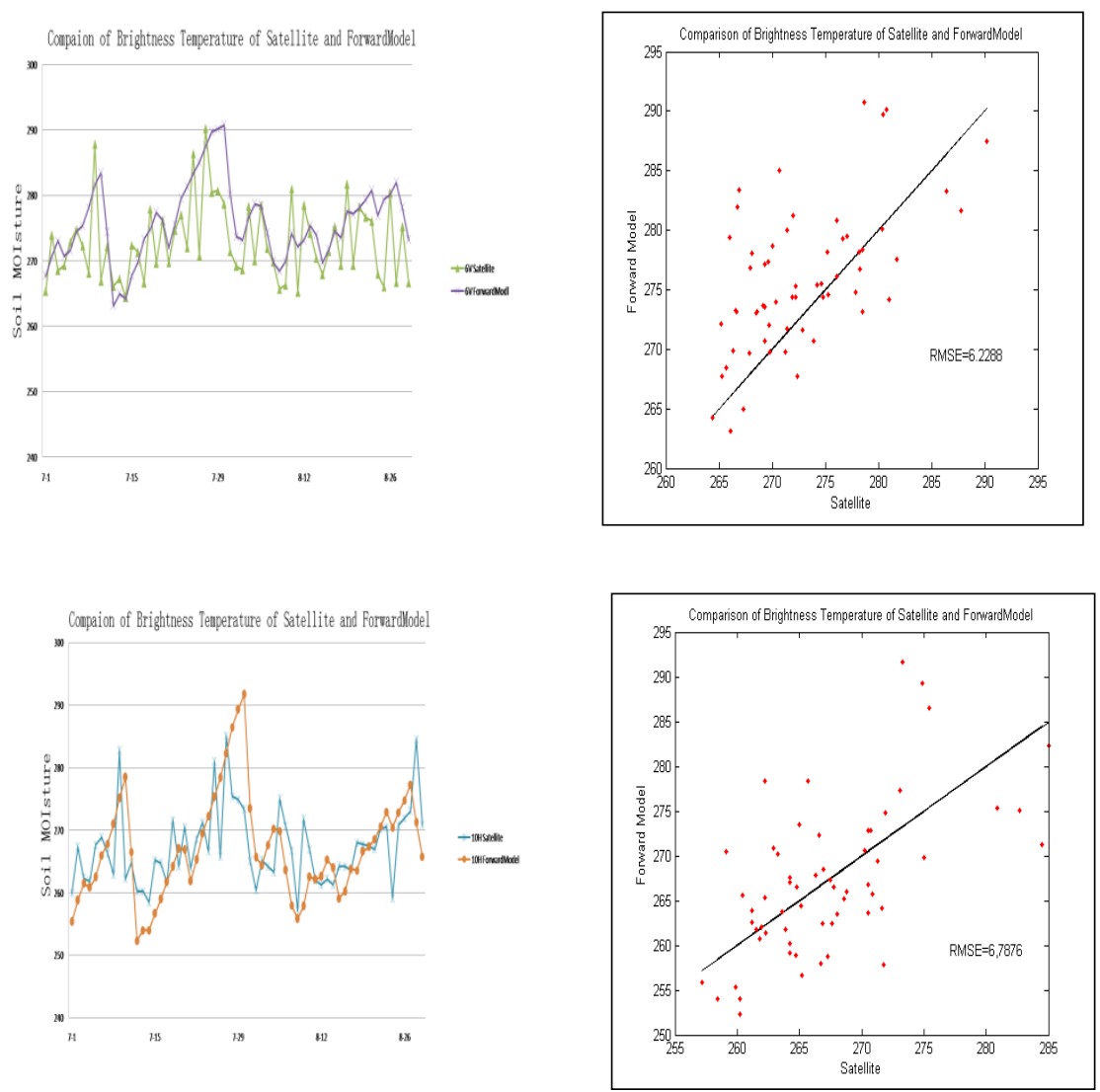

Fig. 3. The study area all pixels in the four channels on the forward simulation results 


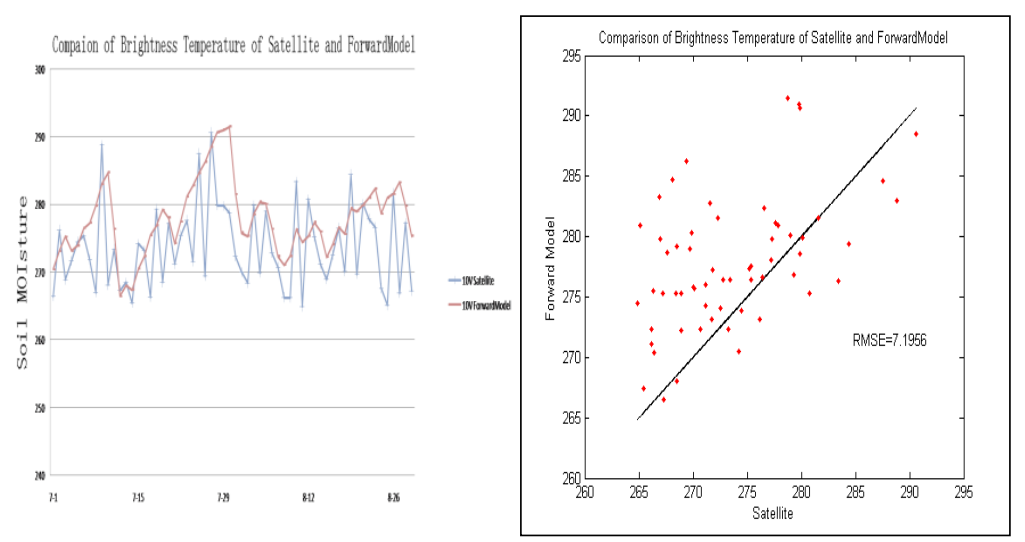

Fig. 3. (Continued)

\subsection{Scatter Meter to Estimate Roughness}

Quikscat / SeaWinds which was launched by FAA work in the Ku band, is different from operating frequency of ESA's wind scatter meter (ESA C-band).In this study, AMSR-E and Quikscat / SeaWinds combined inversion process, the bare surface conditions in the reflectivity of the passive and active backscattering coefficient of each surface parameter sensitivity analysis and found that Quikscat / SeaWinds on the surface the sensitivity of surface roughness parameters was significantly higher than the other, and AMSR-E on the surface roughness of the sensitivity is very low, so try to combine such a passive way: the use of Quikscat / SeaWinds inversion of surface roughness, and then AMSR-E soil moisture and surface temperature inversion. Here is AIEM model simulation Quikscat / SeaWinds bare surface conditions in the backscattering coefficient of a database to analyze its relationship with surface roughness, trying to build a function.

AIEM model simulation with Quikscat / SeaWinds scattering database parameters in Table 1:

Table 1. Input parameters setting for AIEM

\begin{tabular}{|c|c|c|c|c|}
\hline Sensor & Frequency/(GHz) & $\begin{array}{c}\text { Incient angle } \\
\text { and polarization }\end{array}$ & $\mathrm{bd} /\left(\mathrm{g} / \mathrm{cm}^{3}\right)$ & $\begin{array}{c}\text { Surface } \\
\text { correlation } \\
\text { function } \\
\end{array}$ \\
\hline $\begin{array}{l}\text { QuikSCAT/ } \\
\text { Seawinds }\end{array}$ & 13.4 & $46^{\circ} \mathrm{HH}, 54^{\circ} \mathrm{VV}$ & 1.3 & Gaussian \\
\hline $\mathrm{ST} /\left({ }^{\circ} \mathrm{C}\right)$ & $\mathrm{SM} /\left(\mathbf{m}^{3} / \mathbf{m}^{3}\right)$ & $\mathrm{cl} /(\mathbf{c m})$ & sig/(cm) & Soil texture \\
\hline $\begin{array}{l}\text { Range: } 0 \sim 40 \text {, } \\
\text { Interval : } 5\end{array}$ & $\begin{array}{l}\text { Range: } \\
0.02 \sim 0.44 \text {, Interval } \\
: 0.02\end{array}$ & $\begin{array}{l}\text { Range: } \\
12.5 \sim 30 \text {, Interval : } \\
2.5\end{array}$ & \begin{tabular}{l}
\multicolumn{1}{c}{ Range : } \\
$0.25 \sim 3.5, \quad$ Interval \\
0.25
\end{tabular} & $\begin{array}{l}\text { Sand : } \\
47.4 \%, \\
\text { clay : } 5 \%\end{array}$ \\
\hline
\end{tabular}


This study analyzed the surface temperature (st), soil volumetric water content (sm), soil bulk density (bd), roughness (RMS height (sig) and surface correlation length (cl) changes in the value of the latter to scattering coefficient.

The results showed that: the temperature from $0^{\circ}$ to $30^{\circ}$, backscattering coefficient of variation less than $0.05 \mathrm{~dB}$; soil volumetric water content from 0.02 to 0.50 , the backscatter coefficient of variation less than $2.00 \mathrm{~dB}$; soil bulk density from 0.2 to 1.2 , backscattering coefficient of variation less than $1.00 \mathrm{~dB}$; and can change the roughness backscattering coefficient of variation even up to tens of $\mathrm{dB}$.

Based on the above analysis of the results, you can ignore the temperature change caused by changes in the backscattering coefficient, where the fixed temperature of $15^{\circ} \mathrm{C}$, soil bulk density of $0.8 \mathrm{~g} / \mathrm{cm} 3$, a second simulation. The simulation data according to different surface RMS height and correlation length of the configuration group, each change in soil moisture from 0.02 to 0.50 , backscattering coefficient, including a $46^{\circ}$ angle of incidence for the $\mathrm{HH}$ polarization and incidence angle of $54^{\circ}$ the VV polarization, a total of 168 groups. Analysis have shown that, in most cases, the decibel value of two scattering data curves under different soil moisture conditions remain parallel. Due to space limitations, the following list only one of the two-group analysis chart (Fig.4).

Use the second simulation analysis of law get, by two different incidence angles and different polarization of the decibel value of the difference to eliminate the impact of soil moisture and roughness changes to inversion. According to our understanding of the Qinghai-Tibet Plateau region Maqu ground measurement data, that the soil moisture range of 0.2 to 0.5 , roughness, slope $(\mathrm{sig} / \mathrm{cl}$ ) range from 0.04 to 1.0 , select the corresponding simulated data set to analyze the data obtained RMS height and backscatter coefficient and the ratio of two-channel scatter meter decibel difference between the diagram(Fig.5).

According to the variation in Figure 6, the establishment of sig / $\mathrm{cl}$ and $\sigma(\mathrm{dBHH})-\sigma$ $(\mathrm{dBVV})$, exp $(\sigma(\mathrm{dBHH})-\sigma(\mathrm{dBVV}))$ relation by regression analysis of the data to establish the following formula (3):

$$
s i g / c l=0.4231 \cdot \exp [\sigma(d B \mathrm{VV})-\sigma(d B \mathrm{HH})]+0.0034[\sigma(d B \mathrm{VV})-\sigma(d B \mathrm{HH})]+0.109
$$

Correlation coefficient is 0.9692 , standard error is 0.0342 , regression analysis of fitting errors shown in Figure 6.

Here we take the 2008-07-02 global scattering plan the roughness of the estimate slope for example, Let's use of global $\mathrm{HH}, \mathrm{VV}$ polarization scatter meter images to estimate the joint roughness slope, then Maqu region of the $\mathrm{HH}$ and VV scattering count data to estimate the roughness of the slope of the joint (Fig.7).

It can be seen from the figure, Maqu region in July 2 to estimate the roughness of the slope ranges from 0 to 0.5 , consistent with the scope of information. Follow the same steps can be estimated from 2008-07-01 to 2008-08-29 Maqu region a total of 60 days roughness slope. It can be seen from the results, small changes over time, slope roughness, according to the average cycle of a certain treatment, such as ten days, in this time range roughness slope is very small fluctuations over time. 

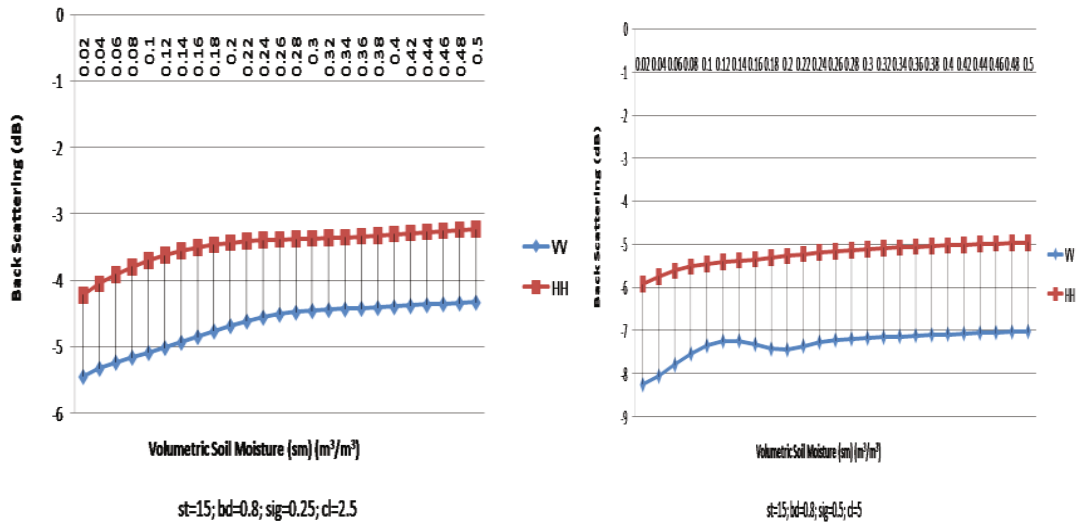

Fig. 4. Different roughness conditions the difference between the backscattering coefficient and soil moisture changes in the relationship between

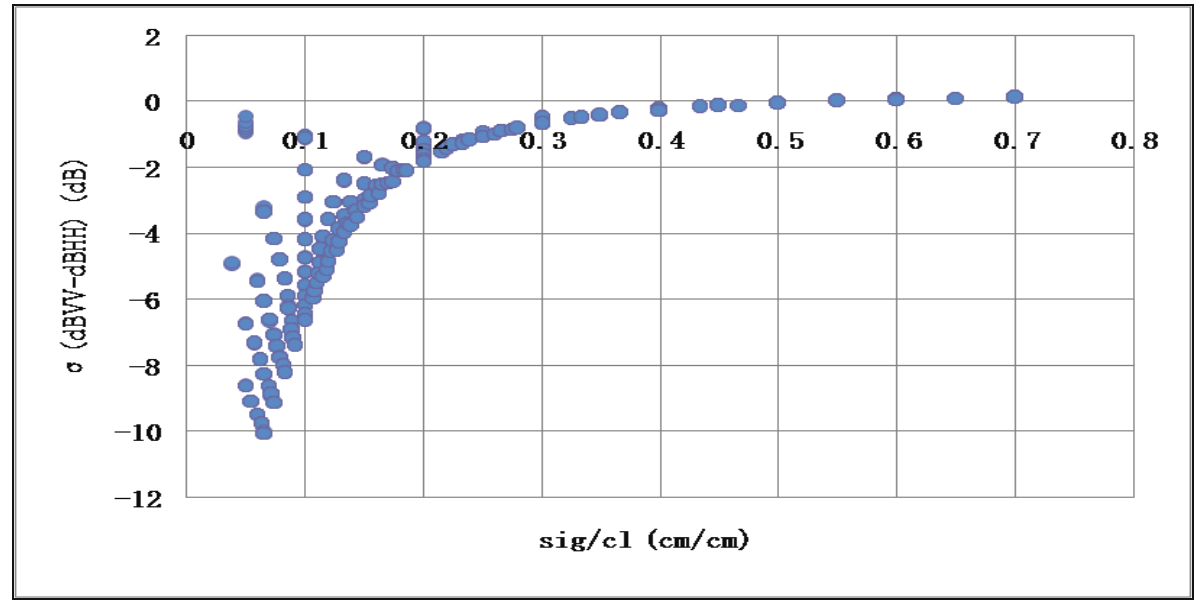

Fig. 5. RMS height and backscatter coefficient and the ratio of two-channel scatterometer decibel difference between 


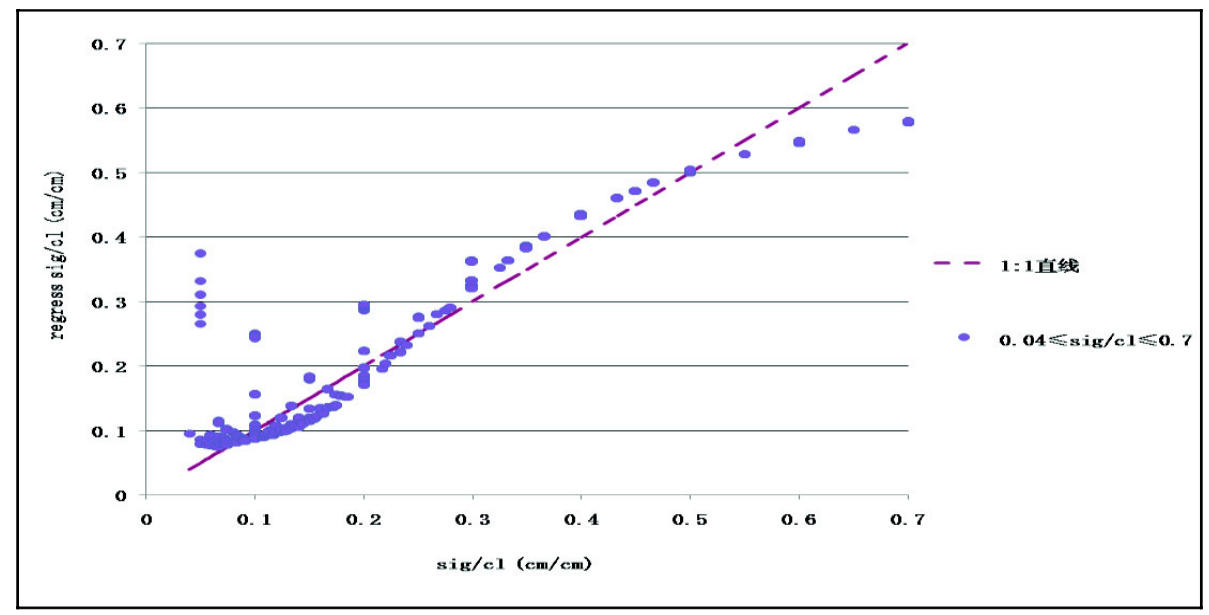

Fig. 6. Statistical regression analysis of fitting error



Fig. 7. With HH and VV Maqu region of scatter meter data to estimate the roughness of the slope image combined

\subsection{Scatter Meter Soil Moisture Inversion}

In the course of the study, due to the frequency when the incident wave near the Cband passive microwave atmospheric effects are negligible; when the frequency gradually increases, the atmospheric effects are also increased. And in order to eliminate measurement noise, where the use of 6 and 10 four-channel two-frequency inversion. Stay inversion of surface parameters to be soil moisture and surface temperature. Iterative inversion algorithm is the LM algorithm. Because of limited space, here only shows the average of all pixel inversion results (Fig.8), which results from the two diagrams: Scatter (left) and sequence diagram (right). 




Fig. 8. The inversion of all pixels and averaging the results of ground truth comparison chart

\section{Conclusions}

Several conclusions can be drawn from our study.

(1) Inversion results has a high fitting accuracy with the ground measurements, indicating that the proposed method can take advantage of the complement of the active and passive microwave data to a certain extent. The scatter meter is more suitable for estimating the impact of surface roughness, and the low-frequency channel of the radiometer is the best choice for SM inversion, and the highfrequency of the radiometer is more relevant to the surface temperature and thus is fit for inversion of ST. Based on these above analysis, this research selects the best combination of observations to retrieve land surface parameters, to achieve a high retrieval accuracy.

(2) The other advantage of importing the Qp model is the active model and the passive model can be linked. This dealing is convenient to make full use of the active/passive's fittest channel to retrieve their most sensitivity land surface parameters.

(3) The proposed method in this research is for the bare soil surface or sparse vegetation cover surface, the surface of higher vegetation cover does not apply to.

Acknowledgment. The work of this paper is supported by the National Natural Science Foundation of China (NO.40701127) and the Beijing Municipal Commission of Education (NO: KM201010028016). The authors wish to thank Dr.Tang bohui of the Institute of Geographic Sciences and Natural Resources Research, CAS for his data and useful comment.

\section{References}

[1] Entekhabi, D., et al.: The Soil Moisture Active Passive (SMAP) Mission. Proceedings of the IEEE 98, 704-716 (2010)

[2] http: / /hydros.gsfc.nasa.gov/ 
[3] Njoku, E.G.: Observations of Soil Moisture Using a Passive and Active LowFrequency Microwave Airborne Sensor During SGP99. IEEE Transactions on Geoscience and Remote Sensing 40, 2659-2673 (2002)

[4] Bolten, J.D., Lakshmi, V., Njoku, E.G.: Soil moisture retrieval using the passive/active L-and S-band radar/radiometer. IEEE Transactions on Geo-science and Remote Sensing 41, 2792-2801 (2003)

[5] Narayan, U., Lakshmi, V., Njoku, E.G.: Retrieval of soil moisture from passive and active L/S band sensor (PALS) observations during the Soil Moisture Experiment in 2002 (SMEX02). Remote Sensing of Environment, Papers 92(4), 483-496 (2004)

[6] Shi, J., Njoku, E.G., Jackson, T., O’Neill, P., Chen, K.S.: Estimation of Soil Moisture with Dual-Frequency-PALS. In: IEEE International Geo-science and Remote Sensing Symposium, vol. 2, pp. 7-11 (2008)

[7] Narayan, U., Lakshmi, V., Jackson, T.J.: High-resolution change estimation of soil moisture using L-band radiometer and radar observations made during the SMEX02 experiments. IEEE Transactions on Geo-science and Remote Sensing 44, 1545-1554 (2006)

[8] Bindlish, R., Jackson, T., Cosh, M., Sun, R., Yueh, S., Dinardo, S.: Combined Passive and Active Soil Moisture Observations During Clasic. In: IEEE International Geoscience and Remote Sensing Symposium, vol. 6, pp. 644-648 (2008)

[9] Piles, M., Entekhabi, D., Camps, A.: A Change Detection Algorithm for Retrieving High-Resolution Soil Moisture From SMAP Radar and Radiometer Observations. IEEE Transactions on Geo-science and Remote Sensing 47, 4125-4131 (2009)

[10] Zhong, R., Guo, H., Wang, W.: Combined passive and active microwave remote sensing of land surface parameters using AMSR-E and Seawinds. In: Proceedings of SPIE (2006)

[11] Scipal, K., Wagner, W., Kidd, R., Ringelmann, N.: Comparison of Ku- and C-band backscatter time series over land. In: IEEE International Geo-science and Remote Sensing Symposium, pp. 24-28 (2002)

[12] Scipal, K., Holmes, T., de Jeu, R., Naeimi, V., Wagner, W.: Error estimation of soil moisture derived from active and passive microwave satellite observations and model data. In: IEEE International Geo-science and Remote Sensing Symposium, vol. 2 (2008)

[13] Mladenova, I., et al.: An Assessment of Quikscat Ku-Band Scatterometer Data for Soil Moisture Sensitivity. IEEE Geo-science and Remote sensing letters 6, 640-643 (2009)

[14] Njoku, E.G., Li, L.: Retrieval of land surface parameters using passive microwave measurements at 6 18 GHz. IEEE Transactions on Geo-science and Remote Sensing, Papers 37(1), 79-93 (1999)

[15] Njoku, E.G., Jackson, T.J., Lakshmi, V., Chan, T.K., Nghiem, S.V.: Soil moisture retrieval from AMSR-E. IEEE Transactions on Geo-science and Remote Sensing 41, 215-222 (2003)

[16] http://nsidc.org/data/amsr_validation/soil_moisture

[17] Chen, K.S., Wu, T.D., Tsang, L., Li, Q., Shi, J.C., Fung, A.K.: The Emission of Rough Surfaces Calculated by the Integral Equation Method with a Comparison to a ThreeDimensional Moment Method Simulations. IEEE Transactions on Geo-science and Remote Sensing 41, 1-12 (2003)

[18] Shi, J.C., et al.: A Parameterized Multifrequency-Polarization Surface Emission Model. IEEE Transactions on Geo-science and Remote sensing 43, 2831-2841 (2005)

[19] Mao, K., Shi, J., Li, Z., Qin, Z., Li, M., Xu, B.: A physics-based statistical algorithm for retrieving land surface temperature from AMSR-E passive microwave data. Science in China (Series D), Papers 50(7), 1115-1120 (2007) 